IZA DP No. 6171

Labor Productivity and Vocational Training:

Evidence from Europe

Hector Sala

José I. Silva

November 2011 


\title{
Labor Productivity and Vocational Training: Evidence from Europe
}

\author{
Hector Sala \\ Universitat Autònoma de Barcelona \\ and IZA
}

José I. Silva

Universitat de Girona

\section{Discussion Paper No. 6171 \\ November 2011}

\author{
IZA \\ P.O. Box 7240 \\ 53072 Bonn \\ Germany
}

Phone: +49-228-3894-0

Fax: +49-228-3894-180

E-mail: iza@iza.org

\begin{abstract}
Any opinions expressed here are those of the author(s) and not those of IZA. Research published in this series may include views on policy, but the institute itself takes no institutional policy positions.

The Institute for the Study of Labor (IZA) in Bonn is a local and virtual international research center and a place of communication between science, politics and business. IZA is an independent nonprofit organization supported by Deutsche Post Foundation. The center is associated with the University of Bonn and offers a stimulating research environment through its international network, workshops and conferences, data service, project support, research visits and doctoral program. IZA engages in (i) original and internationally competitive research in all fields of labor economics, (ii) development of policy concepts, and (iii) dissemination of research results and concepts to the interested public.
\end{abstract}

IZA Discussion Papers often represent preliminary work and are circulated to encourage discussion. Citation of such a paper should account for its provisional character. A revised version may be available directly from the author. 


\section{ABSTRACT \\ Labor Productivity and Vocational Training: Evidence from Europe*}

In this paper we show that vocational training is an important determinant of productivity growth. We construct a multi-country, multi-sectoral dataset, and quantify empirically to what extent vocational training has contributed to increase the growth rate of labor productivity in Europe between 1999 and 2005. We find that one extra hour of training per employee accelerates the rate of productivity growth by around 0.55 percentage points.

JEL Classification: E22, J24, O41

Keywords: continuous vocational training, labor productivity growth

Corresponding author:

Hector Sala

Departament d'Economia Aplicada

Universitat Autònoma de Barcelona

08193 Bellaterra

Spain

E-mail: hector.sala@uab.es

\footnotetext{
${ }^{*}$ Constructive advice from two anonymous referees has contributed to improve this paper. We thank Leonel Muinelo for helpful comments and discussions on earlier versions of it. We also want to thank participants of the 2011 Jornadas de Economía Laboral in Santiago de Compostela (Spain), the 2011 ASSET Meeting in Evora (Portugal) and seminar participants at Universitat Jaume I in Castelló (Spain) for valuable insights. Hector Sala and José I. Silva acknowledge financial support from the Instituto de Estudios Fiscales under the project "Formación, productividad y crecimiento económico en la Unión Europea". We are also grateful to the Spanish Ministry of Science and Innovation for financial support through grant ECO2009-07636.
} 


\section{Introduction}

The fact that economic and productivity growth are driven by human capital and R\&D activities is well established in the literature - see Lucas (1988), Jones (1995), and subsequent literature-. In the presence of accelerating technological change, however, job related training becomes particularly important to allow workers update their skills. This prevents human capital depreciation and warrants an effective use of new technologies imbedded in new equipment (see Acemoglu and Zilibotti, 2001).

Although training decisions have recently received attention in a variety of contexts, the focus of analysis has mainly been placed on the determinants of such decisions, not on their macroeconomic output. ${ }^{1}$ A significant exception is the work by Dearden et al. (2006) where on-the-job training is directly associated with productivity increases. In particular, for a panel of British industries they find that a 1\% increase in work-training rises about $0.6 \%$ the value added per hour and about $0.3 \%$ the hourly wage.

At the aggregate level, the connection between training activities and productivity growth is still a void to be empirically fulfilled. This missing link is a characteristic of relevant studies connecting education and economic growth -for example Barro (1991) and Sala-i-Martin (1997)-. In view that economic growth models could only account for one third of the actual correlation between the level of education and economic growth, Bils and Klenow (2000) argued that a significant part of this correlation is due to omitted variables simultaneously related to these two variables. It is in this context that job training activities seem a natural candidate to be considered. And this is in fact the main task we undertake in this paper. We outline the connection between growth and vocational training by providing evidence on its impact in Europe on the growth rate of average labor productivity.

The main contribution of this paper is to provide a quantitative assessment of the impact of vocational training using a large dataset with information by country and sector, controlling by the standard determinants in the literature such as capital deepening, the level of education, and expenditures in R\&D activities.

Recent literature has shown interest for related issues. From a theoretical perspective,

\footnotetext{
${ }^{1}$ For example, in the context of the wide literature relating training and wages, Albert et al. (2010) examine six countries and claim that wage returns of training may have been traditionally overstated. In the increasingly popular search and matching framework, training decisions in Canada are examined in Caponi et al. (2010) and found to depend on a variety of aggregate and sectoral determinants. Using the same framework, Centeno and Corrêa (2010) argue that the type of technology, whether of the creative destruction or renovative type, is crucial to identify the best investment in human capital. On other grounds, Sousounis and Bladen-Howell (2010) show for the UK that persistence (that is, previous participation in training programmes) is crucial to explain worker's participation in on-the-job training, whereas Grund and Martin (2010) find job status and firm size as the most relevant characteristics for training participation in Germany.
} 
Scicchiato (2010) studies the complementarities between heterogenous human capital and R\&D expenditures. Relevant for us is the fact that human capital, in contrast to the standard practice in economic growth models, is conceived as the outcome of generic education and two types of on-the-job training. It is shown that the composition of this heterogenous human capital is an important determinant of the probability of innovation and, thus, of economic growth. A similar hypothesis is tested in Boothby et al. (2010) for the Canadian industry. Their main finding is that the combination of new technology adoption with on-the-job training shifts the growth rates of productivity. Finally, Madsen (2010) has shown that total factor productivity (TFP) has crucially driven economic growth in the OECD since 1870. When he examines the sources of TFP, he finds the interaction between educational attainment and the distance to the technological frontier as a relevant factor.

The latter result in Madsen (2010) takes us back to Nelson and Phelps (1966). Nelson and Phelps were the first to assert that the more dynamic is the technological pace of an economy, the more human capital is required relative to physical capital. In their model, human capital allows the acceleration of technology diffusion and thereby promotes capital accumulation and economic growth. In a similar spirit, but many years later, Easterly et al. (1994) developed a model in which human capital accumulation is crucial for successful technology adoption. To the extent that vocational training enhances the accumulation of human capital, it seems relevant to attempt an empirical quantification of the growth impact derived from job training activities. Furthermore, Acemoglu and Zilibotti (2001) show that even when all countries have access to the same set of technologies, there will be large cross-country productivity differences on account of technology-skill mismatch. ${ }^{2}$

In this paper, therefore, we take information on training activities for 21 European countries, largely disaggregated across 16 economic sectors, and use it to explore whether continuous vocational training is a relevant driving force of productivity growth. To conduct this analysis we recall Jones (1997), and extend the basic Solow model by including the possibility of skills accumulation by way of job related training at the sectoral level. These training activities are crucial in rising the ability to use more advanced capital goods available in each sector. As a result, the more effort devotes a sector to skill accumulation, the closer it gets to its technological frontier, and the higher the achieved level of labor productivity.

This analysis is particularly relevant in a context of rapid delocalization of industrial activities and large migration flows crucially affecting the advanced and emerging

\footnotetext{
${ }^{2}$ On close grounds, Kemeny (2010) shows that technological upgrading crucially depends on foregin direct investment. Particularly important for us is the finding that the relevance of this link very much depends on the level of social capability (Kemeny, 2010) which can be related to education and training.
} 
economies. To have a sense of how extensive training activities are in Europe, Table 1 informs on the incidence of Continuing Vocational Training (CVT hereafter). CVT courses are training measures or activities which the enterprise finances wholly or partly to their employees having a working contract. ${ }^{3}$ The first column of information shows the percentage of employees participating in CVT courses, while the second one shows the hours spent per participant. The third column combines the first two and provides a global measure of vocational training expressed as total hours in CVT courses normalized by employment (i.e., average hours in CVT courses per employee). This is the key variable of interest in this paper (information on this variable per sector is provided in table 3 below).

Table 1. CVT incidence in Europe. 2005.

\begin{tabular}{|c|c|c|c|c|c|c|c|}
\hline & $\begin{array}{c}\text { Partic }^{1} \\
(\mathrm{~A})\end{array}$ & $\begin{array}{c}\text { Hours }^{2} \\
\text { (B) }\end{array}$ & $\begin{array}{l}\text { Total }^{3} \\
(\mathrm{AxB}) \\
\end{array}$ & & $\begin{array}{c}\text { Partic }^{1} \\
(\mathrm{~A}) \\
\end{array}$ & $\begin{array}{c}\text { Hours }^{2} \\
(\mathrm{~B})\end{array}$ & $\begin{array}{l}\text { Total }^{3} \\
(\mathrm{AxB})\end{array}$ \\
\hline Belgium & 40 & 31 & 12.4 & Hungary & 16 & 37 & 5.9 \\
\hline Czech Rep. & 59 & 23 & 13.6 & Netherlands & 34 & 36 & 12.2 \\
\hline Denmark & 35 & 30 & 10.5 & Austria & 33 & 27 & 8.9 \\
\hline Germany & 30 & 30 & 9.0 & Poland & 21 & 30 & 6.3 \\
\hline Estonia & 24 & 27 & 6.5 & Portugal & 28 & 26 & 7.3 \\
\hline Ireland & 49 & 25 & 12.3 & Slovenia & 50 & 29 & 14.5 \\
\hline Greece & 14 & 25 & 3.5 & Finland & 39 & 25 & 9.8 \\
\hline Spain & 33 & 26 & 8.6 & Sweden & 50 & 34 & 15.6 \\
\hline France & 46 & 28 & 12.9 & U.K. & 33 & 20 & 6.6 \\
\hline Italy & 29 & 25 & 7.3 & Norway & 29 & 32 & 9.3 \\
\hline Luxembourg & 49 & 33 & 16.2 & & & & \\
\hline
\end{tabular}

Notes: $\quad$ 1. Percentage of employees participating in CVT courses; 2. Hours in CVT courses per participant; 3. Hours in CVT courses per employee.

Employees in Luxembourg and Sweden are the most engaged in vocational training courses with more than 15 hours of their time, on average, spent in such courses during a year. This implies that in these two countries each participant spends on these courses around $2.5 \%$ of her annual working time, which amounts to 1920 hours. In Slovenia

\footnotetext{
${ }^{3}$ According to the European CVT survey, the primary objective of these courses is the acquisition of new competencies or the development and improvement of existing competencies. Routine workadjustment training (i.e. basic familiarization with the job, organization or working environment) and routine information passing are excluded. There must be a training mediator (either a person, i.e. a trainer coach or supervisor, or a piece of equipment used for training, i.e. a computer or other training medium). Apprentices and employees without a working contract are excluded from this survey. Finally, unemployed persons receiving job-related training courses financed by the labor market authorities are also excluded from CVT.
} 
and Czech Republic we observe between 12 and 16 hours of CVT per employee (that is, with less than a $25 \%$ gap with respect to Luxembourg, as the leading country), followed by France, Belgium, Ireland and the Netherlands. In turn, Denmark, Finland, Norway, Germany, Austria, and Spain spend between 8 and 12 hours (that is, between a $50 \%$ and a $25 \%$ gap with respect to Luxembourg). Finally, below 8 hours, which is half the highest training intensity per employee, we have Portugal, Italy, U.K., Estonia, Poland, Hungary, and Greece. ${ }^{4}$

When the adequate controls are considered, the role played by vocational training appears as a robust driving force of productivity growth. In particular, following the empirical equation derived from the model, to correctly capture the impact of more intensive training -which is a proxy of increasing ability-, our empirical model controls for (i) the quantity and quality of capital stock -through capital deepening and R\&D expenditures, respectively-; and (ii) for the general quality of labor -through education--

Our central finding is that 1 extra hour of vocational training per employee, other things constant, generates 0.55 additional percentage points of productivity growth. In addition, when the percentage of highly educated workers is increased by 1 percentage point productivity growth is raised by 0.70 extra percentage points. Another relevant factor is progress in capital deepening. When it grows by 1 extra percentage point, the rate of productivity growth is increased by 0.51 percentage points. A final well-known but nevertheless important result is the crucial influence exerted by R\&D expenditures. What it is new in the context of our analysis, is that the influence of this last variable is similar in magnitude to the joint effect of the three factors related to the quality and ability of labor. This joint effect amounts to 1.25 (resulting from the addition of 0.55 , and $0.70)$, whereas 1 extra percentage point of R\&D expenditures over GDP would accelerate the rate of productivity growth by 1.19 percentage points.

These results, in connection to those in the literature overviewed, call for a reappraisal of the policies related to education, active labor market policies, and R\&D activities. The main lesson to be learned is that they cannot be designed in isolation. Conditional on sectorial specificities, job training and R\&D activities should be seen as part of the same set. In turn, human capital accumulation needs to be considered in a broad sense including both generic education and vocational training.

The remaining of the paper is structured as follows. Section 2 develops the theoretical model. Section 3 presents the data and the empirical strategy. Section 4 shows the

\footnotetext{
${ }^{4}$ Due to lack of data, some of these economies cannot be considered in the empirical analysis. These are, in particular some former East European countries such as the Czech Republic, Estonia, Hungary, Poland, and Slovenia which have rates of cumulative productivity growth above $20 \%$. These outstanding performance is very much related to the economic catching up process in which they are still involved. Norway is also excluded, as well as Greece.
} 
empirical results. Section 5 concludes.

\section{The model}

In this section we extend the Jones' model (1997) to analyze the productivity performance of different countries at the sectoral level in a scenario of technology adoption and training. In particular, each sector grows by learning to use the most advanced capital goods that are available in that sector.

We assume an economy of $i$ countries with $j$ sectors producing a homogeneous output $Y_{i, j}$, and using labor $L_{i, j}$ and a range of existing capital goods, $x_{m_{i j}}$. The amount of capital goods $m_{i j}$ that workers can use is limited by the skill level of these workers, $h_{i j}$, which -as shown below- they obtain by participating in job related training activities:

$$
Y_{i, j}=L_{i, j}^{1-\alpha} \int_{0}^{h_{i j}} x_{m_{i j}}^{\alpha} d m .
$$

Equation (1) is the production function of this economy. The integral accounts for the fact that a high-skill level worker is able to use more capital goods than a low-skill level worker. For example, a worker with some hours of training may be able to use computerized machine tools unavailable to workers without training.

The amount of capital goods used within each sector is equal to its total capital stock, $K_{i, j}$. Therefore,

$$
\int_{0}^{h_{i j}} x_{m_{i j}} d m=K_{i j}
$$

We also assume that all capital goods available in each sector are used equally intensively. This implies that $x_{m_{i j}}=x_{i j}$ for all $m_{i j}$ and can be used in equation (2) to determine $x_{i j}=\frac{K_{i j}}{h_{i j}}$. Substitution of this last term in the production function (1) yields an aggregate sectoral production technology taking the familiar Cobb-Douglas form

$$
Y_{i j}=K_{i j}^{\alpha}\left(h_{i j} L_{i j}\right)^{1-\alpha}
$$

As you can see, the training level, $h_{i j}$, enters the equation as a labor-augmenting technology factor.

The worker's skill level in each sector is defined as the range of capital goods that each individual has learnt to use. Thus, when workers of a particular sector receive training and learn to use new machines, economic growth in that sector is enhanced. This learning 
process is characterized by equation (4):

$$
\frac{\dot{h}_{i, j}}{h_{i j}}=\bar{z}_{i j} e^{\psi \xi_{i, j}}\left(\frac{A_{i j}}{h_{i j}}\right)^{\gamma},
$$

where $\bar{z}_{i j}$ is an initial specific level of a worker's ability in each country and sector; $e$ is the exponential function; $\xi_{i j}$ denotes the amount of the worker's time spent in job training; $A_{i j}$ denotes the technological frontier in each country-sector; and $\psi$ and $\gamma$ are parameters such that $0<\psi, \gamma \leq 1$.

This expression indicates that any additional time spent in training activities $\xi$ will increase by $\psi$ the skill level of a worker. The fact that these effects are proportional is driven by the presence of the exponential function $e$ in the equation. Notice that unless there is some initial level of ability, $\bar{z}_{i j}$, it would not be possible to accumulate skill through job related training. This opens the possibility of catching-up with the technological frontier. The last term in equation (4) accounts for the fact that the growth rate of skill progress depends on the distance of the worker's skill level, $h_{i j}$, with respect to the technological frontier $A_{i j}$. The closer this level is to the frontier, the smaller the ratio $\frac{A_{i j}}{h_{i j}}$ and the lower the speed at which skills can be accumulated -or, in other words, the harder it becomes to learn to use capital goods--

We also assume: (i) that the labor force in each sector grows at a constant rate $n_{i j}$; (ii) that aggregate capital in each sector, $K_{i j}$, is accumulated by forgoing consumption so that

$$
\dot{K}_{i j}=s_{i j} Y_{i j}-d_{i j} K_{i j}
$$

where $s_{i j}$ is the constant investment share of output and $d_{i j}$ is the capital depreciation rate in each sector. Following the standard Schumpeterian growth theory -see Madsen (2008) for a discussion-, we assume that the growth of the technological frontier, $A_{i j}$, depends on the fraction of GDP spent on R\&D in each country-sector, $\theta_{i j}$. Thus the technological frontier expands at the rate:

$$
\frac{\dot{A_{i j}}}{A_{i j}}=g_{A_{i j}}=\lambda \theta_{i j} .
$$

Since $h_{i j}$ enters the production function (3) as a labor-augmenting technology factor, the growth rate of $h_{i j}$ will pin down the growth rates of output per worker $y_{i j}=Y_{i j} / L_{i j}$ and capital per worker $k_{i j}=K_{i j} / L_{i j}$. Thus, output per worker becomes

$$
y_{i j}=k_{i j}^{\alpha} h_{i j}^{1-\alpha} .
$$


To solve for the balanced growth path in each country-sector, the growth rate of $h_{i j}$ must be equal to $g_{A_{i j}}$. It turns out, from equation (3), that $\frac{\dot{h}_{i j}}{h_{i j}}$ will be equal to $g_{A_{i j}}$ in the long-run if, and only if, $A_{i j} / h_{i j}$ is constant. Because this requires $h_{i j}$ and $A_{i j}$ to grow at the same rate, the following condition must be satisfied:

$$
g_{y_{i j}}=g_{k_{i j}}=g_{h_{i j}}=g_{A_{i j}}
$$

Hence, the growth rate of each country-sector should converge in the long run to the growth rate of the technological frontier, which in turn depends on policies and other parameters determining the long-run level of R\&D. Solving in equation (4) for the steady state ratio $\left(\frac{h_{i j}}{A_{i j}}\right)^{*}$ we obtain

$$
\left(\frac{h_{i j}}{A_{i j}}\right)^{*}=\left(\frac{\bar{z}_{i j}}{g_{A_{i j}}} e^{\psi \xi_{i j}}\right)^{1 / \gamma} .
$$

Multiplying this ratio by $A_{i j}$ and substituting $h_{i j}$ in equation (7), the sectorial output per worker along the balanced growth path becomes

$$
y_{i j}^{*}=k_{i j}^{* \alpha}\left(\frac{\bar{z}_{i j}}{g_{A_{i j}}} e^{\psi \xi_{i j}}\right)^{\frac{1-\alpha}{\gamma}} A_{i j}^{1-\alpha} .
$$

Following equation (9), the balanced growth path of this economy is driven by three terms. The first one indicates that the larger is the capital per worker ratio $k_{i j}^{*}$, the higher is labor productivity in each country at the sectoral level $y_{i j}^{*}$. The second term reflects the influence of skill accumulation by way of job training activities $\xi_{i j}$, conditional on the initial level of ability $\bar{z}_{i j}$ as well as on the growth rate of the technological frontier, $g_{A_{i j}}$. Notice that $g_{A_{i j}}$ reduces the level of labor productivity through its effect on the workers' skill level. Since $h_{i j}$ captures the labor force capacity to take advantage of the technological frontier, a higher growth rate of this frontier generates a fall in the workers' relative skill level. In this context, the human capital accumulation process is a key mechanism to close the technological gap. ${ }^{5}$ The third term captures the effect of the technological frontier, $A_{i j}$, on labor productivity through expenditures in $\mathrm{R} \& \mathrm{D}$ activities. It generates growth over time in output per worker at the sectoral level.

The central feature of this model is that job related training increases the ability to use more advanced capital goods available in each country-sector. Therefore, sectors that spend more time accumulating skills will be closer to the technological frontier and display higher levels of labor productivity.

\footnotetext{
${ }^{5}$ More details on this interpretation are provided below when we discuss the empirical results.
} 


\section{Data and empirical modelling}

\subsection{Data}

Restricted availability of job training data at the macroeconomic level is surely a key reason behind the lack of studies connecting vocational training and growth. Even though no time-series are yet available, this void has started to be filled with the Continuing Vocational Training Survey (CVTS) made available by Eurostat. Two waves of information are currently available for years 1999 and 2005.

The CVTS documents the degree and intensity of training activities in firms for 25 European countries. However, given data restrictions in other dimensions of our dataset, our sample includes the 21 economies for which information is provided in table 1 .

A key feature of the CVTS is the wide disaggregation by sector of these activities. This is a particularly helpful characteristic in our case, since it crucially augments the number of degrees of freedom and prevents our analysis to run afoul of the critiques raised on the notion of an aggregate production function (Temple, 2006). Indeed, one of the main problems of some studies is the aggregation bias imbedded in their results as a consequence of adding up a variety of economic activities with wide differences in terms of capital- or labor-intensity. In our case, 16 economic activities are distinguished (see the notes in table 3 ).

Given our theoretical model, and conditional on the available information on training per country and sector, we need further data on other variables related to the production function such as value added, employment, net capital stock and the intensity in research and development. Information for these variables is available in the OECD Stan Database. The good news is the coincidence in the breakdown by sector with respect to the Eurostat data on CVT. The bad news is that some countries lack information in some crucial variables. This entails the dismissal of Ireland, Greece, Luxembourg, and Portugal, while for Estonia, Poland, and France some activities will not enter the analysis.

Finally, from the OECD Labour Market Statistics database we gather information on generic education. We use the tertiary level educational attainment for age group 25-64, which is expressed as percent of total employees.

Table 2 defines the variables used in the econometric analysis. As noted in the introduction, our measure of training $\xi_{i j}$ is the average number of hours per employee spent in CVT courses in each country-sector resulting from the combination of the amount of hours spent in such courses per participant and the ratio of participants over employees. This measure, therefore, captures the twofold dimension of improving the ability of workers by getting them more involved in job training, and by training them more intensively. 


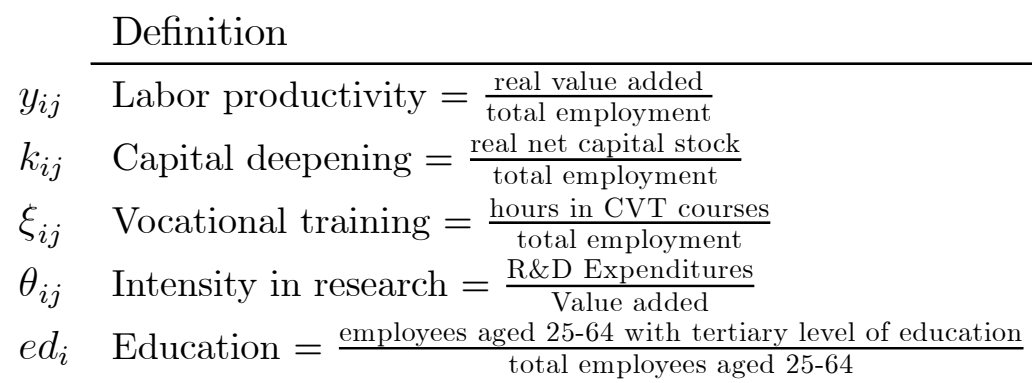

Along the same lines that $\theta$ is generally interpreted as the intensity in research and development, $\xi$ can be interpreted as the intensity in the job training process. In turn, $k$ can be interpreted as the intensity in the degree of capitalization, and ed as the intensity in general education. Our main focus will be on the role played by $\xi$ in explaining labor productivity growth.

In turn, table 3 provides some descriptive statistics on these variables for the 16 sectors of activity included in the analysis (with the exception of $e d$, for which sectoral data is not available). Data on labor productivity, $y$, and capital per worker, $k$, are expressed in cumulative growth rates between 1999 and 2005. Data on vocational training $\xi$ is expressed as additional hours of CVT courses per employee. The level variable $\theta$ is expressed as the average values of these two years. For example, labor productivity and capital per worker grew respectively by $17.4 \%$ and $13.6 \%$ in Sector 1 (mining and quarrying) between 1999 and 2005; while the amount of hours spent in vocational training fell by 6.3 hours per employee. Note, finally, that the large values of the standard deviation in $\Delta \xi$ imply a variation between -13.3 and 13.3 in the training hours received by workers. 
Table 3. Descriptive statistics by sector.

\begin{tabular}{|c|c|c|c|c|c|c|c|c|c|c|c|c|}
\hline & \multicolumn{3}{|c|}{ Sector 1} & \multicolumn{3}{|c|}{ Sector 2} & \multicolumn{3}{|c|}{ Sector 3} & \multicolumn{3}{|c|}{ Sector 4} \\
\hline & $\mu$ & s.d. & $\#$ & $\mu$ & s.d. & $\#$ & $\mu$ & s.d. & $\#$ & $\mu$ & s.d. & $\#$ \\
\hline$\Delta \log y_{i j}$ & 17.4 & 30.0 & 18 & 9.4 & 14.6 & 19 & 17.8 & 20.8 & 19 & 19.6 & 22.0 & $\overline{19}$ \\
\hline$\Delta \xi_{i j}$ & -6.3 & 13.3 & 16 & -1.8 & 2.9 & 19 & -2.2 & 5.2 & 19 & 0.8 & 4.8 & 19 \\
\hline$\Delta \ln k_{i j}$ & 13.6 & 19.0 & 12 & 11.0 & 13.0 & 12 & 22.2 & 16.5 & 12 & 10.8 & 11.4 & 11 \\
\hline \multirow[t]{3}{*}{$\theta_{i j}$} & n.a. & n.a. & 0 & 1.1 & 0.9 & 18 & 1.3 & 1.0 & 18 & 0.5 & 0.4 & 17 \\
\hline & \multicolumn{3}{|c|}{ Sector 5} & \multicolumn{3}{|c|}{ Sector 6} & \multicolumn{3}{|c|}{ Sector 7} & \multicolumn{3}{|c|}{ Sector 8} \\
\hline & $\mu$ & s.d. & $\#$ & $\mu$ & s.d. & $\#$ & $\mu$ & s.d. & $\#$ & $\mu$ & s.d. & $\#$ \\
\hline$\Delta \log y_{i j}$ & 13.6 & 15.5 & 19 & 13.4 & 76.4 & 16 & 17.3 & 17.6 & 19 & 36.9 & 25.8 & 19 \\
\hline$\Delta \xi_{i j}$ & -1.9 & 5.5 & 19 & -0.3 & 6.2 & 19 & 0.6 & 4.8 & 19 & -1.1 & 9.1 & 19 \\
\hline$\Delta \ln k_{i j}$ & 14.1 & 9.1 & 11 & 10.9 & 23.6 & 11 & 10.2 & 10.6 & 11 & 13.7 & 11.3 & 11 \\
\hline \multirow[t]{3}{*}{$\theta_{i j}$} & 0.6 & 0.7 & 17 & 2.6 & 2.7 & 15 & 1.4 & 1.0 & 18 & 10.0 & 6.5 & 18 \\
\hline & \multicolumn{3}{|c|}{ Sector 9} & \multicolumn{3}{|c|}{ Sector 10} & \multicolumn{3}{|c|}{ Sector 11} & \multicolumn{3}{|c|}{ Sector 12} \\
\hline & $\mu$ & s.d. & $\#$ & $\mu$ & s.d. & $\#$ & $\mu$ & s.d. & $\#$ & $\mu$ & s.d. & $\#$ \\
\hline$\Delta \log y_{i j}$ & 27.4 & 24.3 & 19 & 30.0 & 17.0 & 20 & 2.2 & 12.0 & 21 & 16.7 & 15.5 & 20 \\
\hline$\Delta \xi_{i j}$ & -2.9 & 11.1 & 19 & -0.3 & 7.8 & 19 & -2.2 & 5.4 & 19 & -1.2 & 3.8 & 21 \\
\hline$\Delta \ln k_{i j}$ & 14.4 & 11.6 & 12 & 10.7 & 12.4 & 13 & 13.8 & 11.4 & 13 & 9.6 & 10.5 & 13 \\
\hline \multirow[t]{3}{*}{$\theta_{i j}$} & 8.5 & 7.8 & 18 & 0.4 & 0.5 & 18 & 0.2 & 0.1 & 18 & 0.2 & 0.2 & 16 \\
\hline & \multicolumn{3}{|c|}{ Sector 13} & \multicolumn{3}{|c|}{ Sector 14} & \multicolumn{3}{|c|}{ Sector 15} & \multicolumn{3}{|c|}{ Sector 16} \\
\hline & $\mu$ & s.d. & $\#$ & $\mu$ & s.d. & $\#$ & $\mu$ & s.d. & $\#$ & $\mu$ & s.d. & $\#$ \\
\hline$\Delta \log y_{i j}$ & -6.8 & 13.9 & 20 & 29.9 & 34.2 & 20 & -5.7 & 11.0 & 20 & 3.6 & 14.6 & 20 \\
\hline$\Delta \xi_{i j}$ & -2.4 & 4.7 & 19 & 0.04 & 8.4 & 21 & -4.6 & 7.3 & 21 & 0.05 & 7.0 & 21 \\
\hline$\Delta \ln k_{i j}$ & 0.8 & 10.8 & 13 & 5.3 & 18.4 & 13 & -6.7 & 8.1 & 13 & 13.3 & 23.1 & 13 \\
\hline$\theta_{i j}$ & 0.004 & 0.01 & 13 & 0.3 & 0.3 & 15 & 0.9 & 0.7 & 17 & n.a & n.a & 0 \\
\hline \multicolumn{13}{|c|}{$\mu=$ Mean (in percentage, except hours); s.d. = Standard deviation; \# = Observations. } \\
\hline \multicolumn{13}{|c|}{$\begin{array}{l}\text { Sectors: (1) Mining and quarrying; (2) Food products, beverages and tobacco; (3) Textiles, } \\
\text { textile products, leather and footwear; (4) Wood and products of wood and cork; (5) Pulp, } \\
\text { paper, paper products, printing and publishing; (6) Coke, refined petroleum products and } \\
\text { nuclear fuel; (7) Basic metals and fabricated metal products; (8) Machinery and equipment; } \\
\text { (9) Transport equipment; (10) Electricity, gas, and water supply; (11) Construction; } \\
\text { (12) Wholesale and retail trade - repairs; (13) Hotels and restaurants; (14) Financial }\end{array}$} \\
\hline
\end{tabular}




\subsection{Empirical modelling}

Available data allows us to work with a three-dimensional panel data where the same sectoral $i$ and cross country units $j$ are observed for two years, $t_{0}=1999$ and $t_{1}=2005$. Thus, applying logarithms to equation (9) and using equation (6), we obtain the following two-periods model

$$
\begin{aligned}
\ln y_{i j}(t)= & \alpha \ln \left(k_{i j}(t)\right)+\frac{(1-\alpha) \psi}{\gamma} \xi_{i j}(t)+\frac{(1-\alpha)}{\gamma} \ln \left(\bar{z}_{i j}\right) \\
& +(1-\alpha) \ln \left(A_{i j}(t)\right)+\frac{(\alpha-1)}{\gamma} \ln \left(\theta_{i j}(t)\right)+\frac{(1-\alpha)}{\gamma} \ln (\lambda)
\end{aligned}
$$

However, since information on the initial sectoral level of ability, $\bar{z}_{i j}$, the previous equation needs to be transformed into the following unobserved effects model:

$$
\ln y_{i j}(t)=\beta_{0}+\beta_{1} \ln \left(k_{i j}(t)\right)+\beta_{2} \xi_{i j}(t)+a_{i j}+\beta_{3} \ln \left(A_{i j}(t)\right)+\beta_{4} \ln \left(\theta_{i j}(t)\right)+u_{i j}(t)
$$

where $a_{i j}$ is a unit-specific effect (i.e., a fixed effect accounting for unobserved heterogeneity) that captures all unobserved time-invariant factors that may affect labor productivity, $y_{i j}$. Here, for example, we could include elements such as the managerial style in each country-sector. The idiosyncratic error, $u_{i j}$, represents all unobserved factors that vary over time.

As a last step, we take first differences in order to eliminate the unobserved heterogeneity. We thus differentiate equation (11) and, using equation (6), replace $\Delta \ln \left(A_{i j}(t)\right)$ by $\lambda \theta_{i j}$ to obtain

$$
\Delta \ln y_{i j}=\delta_{0}+\beta_{1} \Delta \ln k_{i j}+\beta_{2} \Delta \xi_{i j}+\beta_{3} \theta_{i j}+\beta_{4} \Delta \ln \theta_{i j}+\Delta u_{i j}
$$

where $\Delta$ denotes change in the variable from $t_{0}=1999$ to $t_{1}=2005$. Notice that in a context of a two-period panel data, taking first differences is equivalent to discard the time dimension of our initial three-dimensional panel data.

This is important for a twofold reason. First, it makes economic sense since equation (12) allows for an explicit consideration of how changes in the stock of capital per worker, job training as well as the level and growth rate of $R \& D$ affect the change in labor productivity over time. Second, it makes econometric sense since by eliminating the time dimension we are left with a two-dimensional panel data model where sectors are the central dimension of analysis. 


\section{Estimated equations}

Our empirical specification (12) is expressed in first differences to account for the possibility of time-invariant unobservable determinants of the dependent variable. The fact that this difference is taken on a six-year time spell guarantees enough variability for the estimation to be conducted. Moreover, the other two dimensions of our panel -countries and sectors-, supply additional sources of variation within each cross-section unit. In terms of estimation, our database is organized such that the cross-section dimension of the panel corresponds to sectors.

Our first estimate of equation (12) consists of a pooled model for which we employ pooled and feasible least squares estimators. Pooled least squares are used to estimate models 1 to 5 . We start from the simplest specification -Model 1 [M1] in table 4- and sequentially add up control variables so as to complete our selected specification -[M5] in table 4-. For the control variables expressed in levels, we consider their average values in 1999 and 2005 because these provide the closest representation of the period under scrutiny.

Since the Feasible General Least Squares (FGLS) estimator is asymptotically more efficient than the pooled OLS estimator when the series exhibit heteroskedasticity (Wooldridge 2006, p. 292), our final specification M5 is also estimated by FGLS. In particular, crosssection weights are used in Models 6 and 7 to correct, respectively, for country and sectoral cross-section heteroskedasticity.

Regarding the estimated coefficients, the first noteworthy characteristic is the robustness of the crucial estimated parameters. The first specification, M1, only considers $\Delta \xi_{i j}$ as regressor and thus takes advantage of all available data points (293). It yields an estimated coefficient of 0.40 implying that 1 extra hour of training per employee generates 0.40 additional percentage points of productivity growth. The addition of capital deepening, $\Delta \ln k_{i j}$, reduces the number of observations, but allows a much better fit of the model. The coefficient on $\Delta \xi_{i j}$ remains highly significant and is placed at 0.24 . This value remains highly stable with the addition in M3 of research and development expenditures, $\theta_{i j}$; and then of the change in research and development expenditures, $\Delta \ln \theta_{i j}$ in M4; but it rises to 0.53 with the addition of education, ed, in M5. When the FGLS estimator is employed the estimated coefficient on $\Delta \xi_{i j}$ maintains its value above 0.50. Nevertheless, it is worth noting that its maximum significance is achieved when we correct for crosssection sector heteroskedasticity in M7. Given that this specification also yields the best fit, our reference estimate is 0.55 .

This last specification of the model coincides with the largest estimated coefficient for capital deepening, which attains 0.51 in front of the values around 0.40 in the previous 
specifications. This implies that a 1 percentage point increase in the growth rate of capital deepening (i.e., in the growth rate of the ratio between capital stock and employment) accelerates productivity growth by 0.51 percentage points. In other words, other things equal, more than half of the acceleration in capital deepening is directly translated into enhanced labor efficiency. Even more important as determinant of labor efficiency are expenditures in R\&D. According to our estimates, one extra percentage point spending in $R \& D$ accelerates productivity growth by 1.2 percentage points.

Table 4. Pooled model. Results.

Dependent variable: $\Delta \ln y_{i j}$

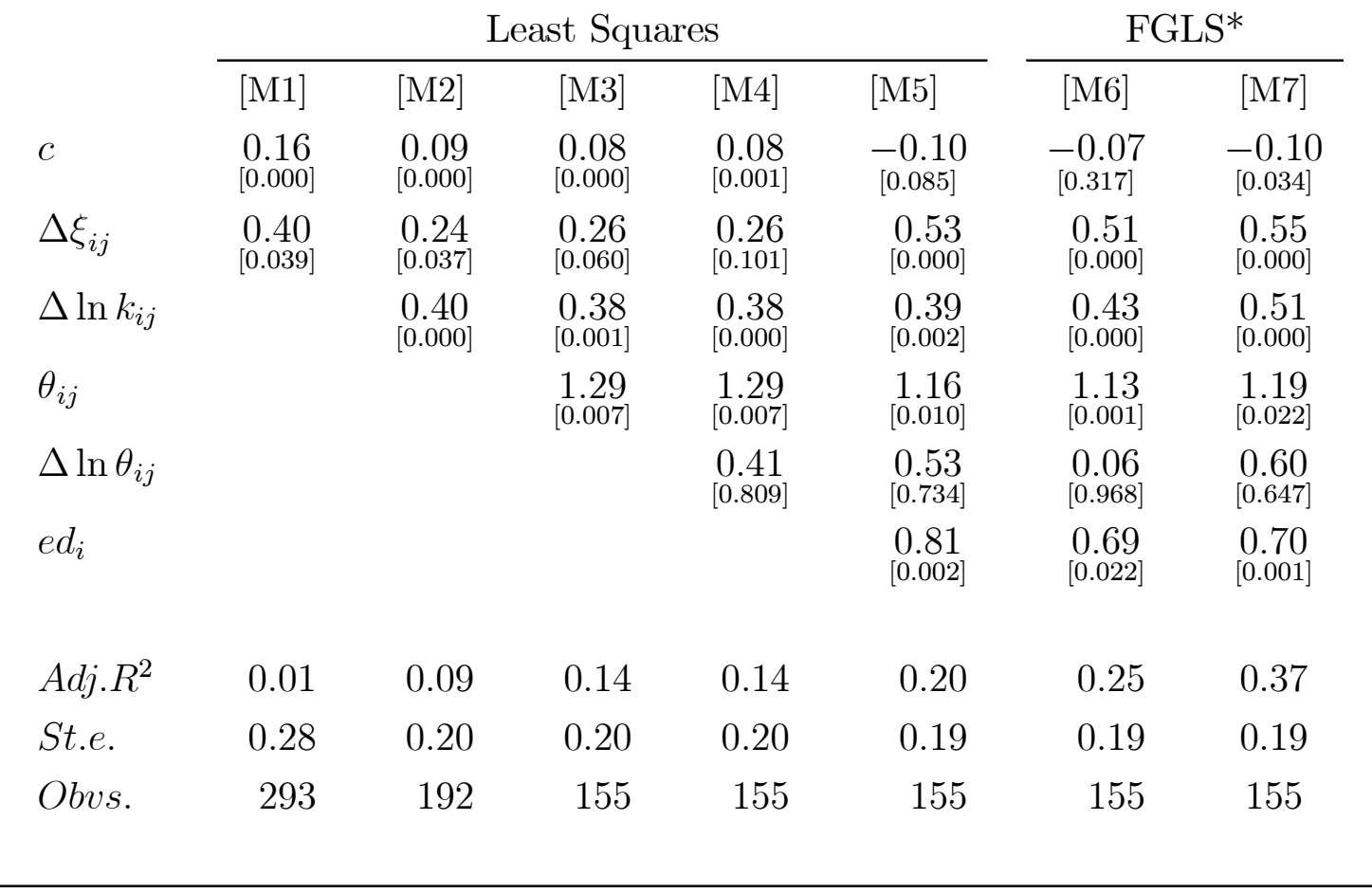

* FGLS: Feasible Generalized Least Squares. M denotes model. Model 6 uses cross-section country weights. Model 7 uses cross-section sector weights. p-values in brackets.

No matter the empirical specification of the model, the change in R\&D expenditures, $\Delta \ln \theta_{i j}$, appears as not significant. Recall that our model takes $h$ as a measure of the existing technological gap -that is, of the distance between the current level of technology and the technological frontier--. As such, $h$ might be understood as the degree of utilization of the current level of technology at a given technological frontier. When the growth rate of $\mathrm{R} \& \mathrm{D}$ expenditures increases, the technological gap becomes larger and generates a deviation with respect to potential productivity growth. If this loss is empirically relevant, we should expect a significant negative sign on this variable. However, it turns out to 
be non-significant. We interpret this result as a reflection of rapid adjustments, across sectors, to the technological frontier. If this is the case, then the fact that technological gaps are quickly closed is probably a reflection of a fast adoption of new technologies which, as we have seen, is clearly enhanced by vocational training. ${ }^{6}$

The final control variable is related to the quality and enhanced ability of labor. Education has a coefficient of 0.70 which in contrast with the one on capital deepening, decreases when cross-section country and sector heteroskedasticity is taken into account. This corroborates the model's predictions to the extent that better qualifications have a significant positive impact on productivity growth.

Education is the only variable not explicitly considered in the theoretical model. The reason for adding general education as a control variable is to take into account potential positive effects on productivity stemming from the general qualification in each economy of the available manpower (recall that this information is not available by sectors). Apart from being empirically relevant, considering ed as an extra control variable contributes to rise the training coefficient from around 0.25 to above 0.50 . We interpret this increase as reflecting the additional possibilities that training has in a context of higher human capital (that is, the more educated the employees are, the more productive becomes any additional training).

It is also interesting to observe that, jointly, the two factors related to the quality and ability of labor have a similar positive impact on improving the efficiency of the economy than the widely studied impact of $R \& D$ expenditures (1.25, resulting from the addition of 0.55 and 0.70 , versus 1.19 ). Note that this result is also quite robust across estimation methodologies. The difference is that the joint effect from the labor side is somewhat larger in M5 (it amounts to 1.34), and smaller when employing the FGLS estimator in M6 and M7 (1.20 and 1.25, respectively).

Next we investigate the possibility of introducing an additional control for sector fixedeffects. The intuition behind this possibility is the distinct production technology characterizing those sectors. Think, for example, on machinery and equipment (sector 8) as compared with hotels and restaurants (sector 13). Depending on the structure of the economy (i.e., on the sectors of specialization), differences in the production function of these sectors affect the speed at which countries tend to converge to their technological frontier, and could be relevant in determining their productivity growth.

\footnotetext{
${ }^{6}$ Although in the context of our model the presence of the change in R\&D expenditures is related to the technological gap, the simultaneous presence of the level and change of this variable gives rise to an empirical test on the prominence of first-generation Schumpeterian growth models -where it is the level of $R \& D$ which directly enhances growth- versus the semi-endogenous ones -where it is the change in $R \& D$ what matters. Taken at face value, our results provide empirical support for the first class of growth models, along the lines of Madsen (2008). We should also point out that the change in R\&D expenditures remains non-significant even when the level is excluded from the regression.
} 
Let us note that economic growth equations are generally estimated as fixed-effects models on account of the larger within variance. In terms of growth analyses, this standard practice is justified on the grounds of the larger within-country variability (across the time dimension of the panel) than the between-country variability (across the cross-section or, equivalently, cross-country dimension). Here, in contrast, the time dimension of the panel has been suppressed. Hence, to clarify next exercise let us write the following general model

$$
y_{i j}=\alpha+\boldsymbol{\beta} \mathbf{X}_{i j}+u_{i j}
$$

where $i$ denotes sector, $j$ denotes country, $\alpha$ is a common constant, $\mathbf{X}$ is the vector of explanatory variables, and the residual $u_{i j}$ has three components -a sector-specific one $\mu_{i}$, a country-specific one $\varepsilon_{j}$, and a common one $\varepsilon_{i j}$ so that $u_{i j}=\mu_{i}+\lambda_{j}+v_{i t}$.

We compute the within variance (across sectors) and find it to be 0.25 and larger than the between variance (across countries) which amounts to 0.12 . This evidence leads us to start the estimation of equation (13) as a one-way fixed-effects model such as: ${ }^{7}$

$$
y_{i j}=\left(\alpha+\mu_{i}\right)+\boldsymbol{\beta} \mathbf{X}_{i j}+\overbrace{\left(\lambda_{j}+v_{i t}\right)}^{u_{i j}}
$$

The results of this regression are presented in Table 5 as M8. Before discussing them, however, we check whether these country effects are significant or not. For this we use a redundant fixed effect test (Chamberlain, 1984) that evaluates the joint significance of the fixed-effects using the likelihood function ( $\chi^{2}$ test). It yields a value of 34.49. When compared with a $\chi^{2}(13)=22.36$ (because we have 14 sectors and test 13 restrictions) we reject the null of redundant sector fixed-effects.

Rejection of the null does not imply acceptance of the alternative. Therefore, because the possibility of random-effects has actually not been evaluated, next we regress our empirical as a one-way random-effects model and perform a Hausman test to check whether sector fixed-effects are preferred over sector random-effects. It turns out that the null of no misspecification (that is, of no correlation between the individual effects and the explanatory variables) is not accepted and thus we can cannot dismiss the possibility of significant random-effects. The corresponding results are also shown in Table 5 as M9.

While fixed-effects only capture the variability stemming from sectors, random effects account for both the variability stemming from sectors and countries. Although the

${ }^{7}$ The estimation of a two-way fixed-effects model would imply regressing

$$
y_{i j}=\left(\alpha+\mu_{i}+\lambda_{j}\right)+\boldsymbol{\beta} \mathbf{X}_{i j}+v_{i t} .
$$

However, one of the variables - education ed-is country invariant and impedes the estimation of such model on account of multiple collinearity. 
first one is larger, the second one is not negligible. Therefore, beyond the results of the Hausman test, we believe random effects to be a plausible modeling assumption in a case, such as ours, of a two-dimensional panel containing sectors and countries, and not time. Country variability may well be the outcome of differences in terms of the institutional setting in which firms (across sectors) operate. This would also affect the speed at which different sectors in different economies tend to converge to their technological frontier, and could also be relevant in determining their productivity growth.

Table 5. One-way fixed-effects and random-effects models. Results.

Dependent variable: $\Delta \ln y_{i j}$. Method: Pooled Least Squares.

\begin{tabular}{|c|c|c|c|c|c|c|c|c|}
\hline \multirow[b]{2}{*}{$c$} & \multirow{2}{*}{$\begin{array}{c}{[\mathrm{M} 8]} \\
-0.08 \\
{[0.289]}\end{array}$} & \multirow{2}{*}{$\begin{array}{l}{[\mathrm{M} 9]} \\
-0.09 \\
{[0.150]}\end{array}$} & \multicolumn{6}{|c|}{ Country effects: } \\
\hline & & & & F.E. & R.E. & & F.E. & R.E. \\
\hline$\Delta \xi_{i j}$ & $\begin{array}{c}0.37 \\
{[0.000]}\end{array}$ & $\begin{array}{c}0.45 \\
{[0.000]}\end{array}$ & Sector 2 & -0.022 & -0.014 & Sector 09 & -0.088 & -0.040 \\
\hline$\Delta \ln k_{i j}$ & $\begin{array}{c}0.32 \\
{[0.060]}\end{array}$ & $\begin{array}{c}0.36 \\
{[0.012]}\end{array}$ & Sector 3 & 0.066 & 0.027 & Sector 10 & 0.132 & 0.071 \\
\hline$\theta_{i j}$ & $\begin{array}{c}1.38 \\
{[0.062]}\end{array}$ & $\begin{array}{c}1.24 \\
{[0.028]}\end{array}$ & Sector 4 & 0.067 & 0.026 & Sector 11 & -0.130 & -0.070 \\
\hline$\Delta \ln \theta_{i j}$ & $\begin{array}{c}-1.16 \\
{[0.346]}\end{array}$ & $\begin{array}{c}-0.03 \\
{[0.985]}\end{array}$ & Sector 5 & 0.008 & 0.001 & Sector 12 & 0.039 & 0.018 \\
\hline$e d_{i}$ & $\begin{array}{c}0.70 \\
{[0.011]}\end{array}$ & $\begin{array}{c}0.77 \\
{[0.004]}\end{array}$ & Sector 6 & 0.036 & 0.020 & Sector 13 & -0.172 & -0.061 \\
\hline & & & Sector 7 & -0.019 & -0.010 & Sector 14 & 0.128 & 0.055 \\
\hline $\operatorname{Adj} . R^{2}$ & 0.30 & 0.17 & Sector 8 & 0.029 & 0.018 & Sector 15 & -0.088 & -0.041 \\
\hline St.e. & 0.18 & 0.18 & & & & & & \\
\hline Obvs. & 155 & 155 & & & & & & \\
\hline
\end{tabular}

Notes: same sectors than in Table 2; p-values in brackets; M denotes model;

F.E.=Fixed-effects; R.E.=Random-effects; M8 and M9 are, respectively, the F.E. and R.E. models.

The estimated models in M8 and M9 show significant differences in two dimensions. First, the adjusted $R^{2}$ is notably higher in M8 than in M9 (0.30 versus 0.17$)$. Second, with the exception of $\Delta \xi_{i j}$ and $e d_{i}$, which are equally significant irrespective of the modeling assumption, the rest of the variables are much less significant in M8. The key result for us, however, is the robustness of the estimated coefficient for $\Delta \xi_{i j}$, which is 0.37 under under fixed-effects, and 0.45 in the random-effects model. Another important feature is the similarity of the results in M5 and M9. This should come as no surprise since the estimation of M9 does not allow to correct neither for country nor sector heteroskedasticity, which was the case in the FGLS estimates presented in M6 and M7. Were random-effects 
not considered, these sector specific effects would be accounted for by the residual. In that case we would be back to the estimated parameters in Model 5. Observe, also, that the sum of the coefficients related to human capital amounts to 1.22 (by the addition of 0.45 and 0.77 ) and is still similar to the coefficient of 1.24 related to the effect of the $R \& D$ intensity.

In view of the robust results obtained across different models and estimation methodologies, the choice of a preferred output is relatively harmless. Given that model 7 provides the best fit to the data and all the estimated coefficients are highly significant (with the sole exception of the change in $R \& D$ expenditures), were we to choose a set of results those from M7 would be the selected ones.

\section{Conclusions}

In today's globalized economies, competitiveness is more than ever a crucial concept. With Europe gradually emerging from the crisis, the EU and its Member States have set in 2011 the Europe 2020 strategy for a new growth path. Five objectives related to employment, innovation, education, social inclusion and climate/energy have been set at the EU level. The Member States have to translate them into national targets.

This paper shows that vocational training could well be a relevant indicator for achieving the first three targets of the European strategy for this decade. We have shown that it is a source of comparative advantages to promote growth in labor productivity and it is well known that labor productivity is a key determinant of competitiveness and growth.

In the context of an extended Solow-type model, consideration of continuous technological adoption and job training allows us to show that better access to relevant vocational training enables more workers to benefit from technological progress and increase their labor productivity.

At the empirical level we have quantified the effect of continuing vocational training (CVT) on productivity growth. Using information for years 1999 and 2005, 16 sectors of activity, and 21 European economies we find that one extra hour of training per employee contributes to accelerate the growth rate of labor productivity by 0.55 percentage points. This impact is similar to the one from capital deepening, which amounts to 0.51 percentage points. In addition, when the proportion of highly educated workers is increased by 1 percentage point, productivity growth is raised by 0.70 extra percentage points. We also find that these two indicators related to the quality and ability of labor -i.e., vocational training and general education- are jointly as important in accelerating economic efficiency as the level of R\&D expenditures, whose effect amounts to 1.2 percentage points.

Overall, vocational training should be considered as an important policy tool to en- 
sure a fair and efficient adjustment process to technological changes. A progressive drift towards a global design of policy measures related to both $\mathrm{R} \& \mathrm{D}$ activities and vocational training seems thus desirable. And given its complementarities with general education in fostering the accumulation of human capital, such global design should also include general education as a first step in this process. In terms of the current EU strategy, job training activities should not be disregarded as a central ingredient in the interplay of measures related to the employment, innovation and education targets set in the context of the new European growth agenda.

To conclude, it is worth noting that this analysis provides a stepping stone towards a better understanding of the role played by job training in enhancing labor productivity growth. We have analyzed a reduced form model where training is exogenous and not a choice variable for firms. Further research should aim at the endogenization of this variable so as to gain more insights on the crucial relationship between workers' training and economic efficiency. One possibility would be to expand the model of schooling and growth proposed by Bils and Klenow (2000), where investments in human capital are modelled as a decision on the worker's side, to explicitly incorporate firm's decisions on vocational training.

\section{References}

[1] Acemoglu, D. and F. Zilibotti (2001): "Productivity differences", The Quarterly Journal of Economics, vol. 116(2), pp. 563-606.

[2] Albert, C., C. García-Serrano, V. Hernanz (2010): "On-the-job training in Europe: Determinants and wage returns", International Labour Review, vol. 149 (3), pp. 315-341.

[3] Barro, R.J. (1991): "Economic Growth in a Cross Section of Countries", Quarterly Journal of Economics, vol. 106(2), pp. 407-443.

[4] Bils, M. and P. Klenow (2000): "Does Schooling Cause Growth?", The American Economic Review, vol. 90 (5), pp. 1160-1183.

[5] Boothby, D., A. Dufour, and J. Tang (2010): "Technology adoption, training and productivity performance", Research Policy, vol. 39, pp. 650-661.

[6] Caponi, V., Kayahan, B., and M. Plesca (2010): "The Impact of Aggregate and Sectoral Fluctuations on Training Decisions," The B.E. Journal of Macroeconomics, vol. 10 (1), Advances, Article 28.

[7] Centeno, M. and M. Corrêa (2010): "Job matching, technological progress, and workerprovided on-the-job training", Economics Letters, vol. 109(3), pp. 190-192.

[8] Chamberlain, G., (1984): "Panel data", in Griliches, Z. and M. Intriligator (Eds.) Handbook of Econometrics, Vol. 2. North-Holland, Amsterdam, pp. 1247-1318. 
[9] Dearden, L., H. Reed, and J. Van Reenen (2006): "The impact of training on productivity and wages: Evidence from British Panel Data", Oxford Bulletin of Economics and Statistics, vol. 68 (4), pp. 397-421.

[10] Easterly, W., R. King, R. Levine, and S. Rebelo (1994): "Policy, Technology Adoption, and Growth", NBER Working Paper no. 4681. Cambridge, MA: National Bureau of Economic Research.

[11] Eurostat: http://epp.eurostat.ec.europa.eu/portal/page/portal/statistics/search_database.

[12] Grund, C. and Martin, J. (2010): "Determinants of Further Training: Evidence for Germany", IZA Discussion Paper no. 5315, IZA, Bonn.

[13] Jones C. (1995): "R\&D-based models of economic growth", Journal of Political Economy, vol. 103, pp. 759-784.

[14] Jones C. (1997): Introduction to Economic growth. W.W Norton \& Company, Inc. New York, United States of America.

[15] Kemeny, T. (2010): "Does Foreign Direct Investment Drive Technological Upgrading?", World Development, Vol 38 (11), pp. 1543-1554.

[16] Lucas, R.E.Jr. (1988): "On the Mechanics of Economic Development", Journal of Monetary Economics, vol. 22, pp. 3-42.

[17] Madsen, J.B. (2008): "Semi-endogenous versus Schumpeterian growth models: testing the knowledge production function using international data", Journal of Economic Growth, vol. 13, pp. 1-26.

[18] Madsen, J.B. (2010): "The anatomy of growth in the OECD since 1870", Journal of Monetary Economics, vol. 57, pp. 753-767.

[19] Nelson, R.R. and E.S. Phelps (1966): "Investment in Humans, Technological Diffusion, and Economic Growth", The American Economic Review Papers and Proceedings, 56, pp. 69-75.

[20] Sala-i-Martin, X. (1997): "I Just Ran Four Million Regressions", National Bureau of Economic Research (Cambridge, MA) Working Paper No. 6252, November 1997.

[21] Scicchitano, S. (2010): "Complementarity between heterogeneous human capital and R\&D: can job-training avoid low development traps?", Empirica, vol. 37, pp. 361-380.

[22] Sousounis, P. and R. Bladen-Howell (2010): "Persistence in the determination of workrelated training participation: Evidence from the BHPS, 1991-1997", Economics of Education Review, vol. 29, pp. 1005-1015.

[23] Temple, J.R.W. (2006): "Aggregate production functions and growth economics", International Review of Applied Economics, vol. 20 (3), pp. 301-317.

[24] Wooldridge, J. (2006): Introductory Econometrics. A Modern Approach, 3rd edition, Thompson South-Western. 